\title{
CRISIS SANITARIA Y MODELO AUTONÓMICO
}

\author{
Piedad García-Escudero Márquez \\ Catedrática de Derecho Constitucional, \\ Universidad Complutense de Madrid
}

\begin{abstract}
Cómo citar este artículo / Citation: García-Escudero Márquez, P. (2021). Crisis sanitaria y modelo autonómico. Tudela Aranda, J. (coord.)

Estado Autonómico y covid-19, Colección Obras colectivas, Fundación Manuel Giménez Abad, Zaragoza.

DOI: https://doi.org/10.47919/FMGA.OC21.0206
\end{abstract}

\begin{abstract}
SUMARIO: I. AUTONOMÍA VERSUS COOPERACIÓN - II. SUSPENSIÓN O RESTRICCIÓN DE DERECHOS FUNDAMENTALES - III. RELACIONES INTERGUBERNAMENTALES Y COMPETENCIAS PARLAMENTARIAS - IV. HACIA EL FUTURO
\end{abstract}

\section{AUTONOMÍA VERSUS COOPERACIÓN}

Si los dos principios en torno a los cuales gira el funcionamiento de un Estado compuesto son autonomía y cooperación, podría decirse que hasta la crisis sanitaria que marca el año 2020, el énfasis, -muchas veces insistente y exigente- se había puesto sobre la autonomía. Sabemos que los extremos Estado federal-Estado unitario tienden a aproximarse en el centro a medida que el primero se centraliza, en particular como consecuencia de las grandes crisis -el New Deal americano post 1929, las postguerras- o de las exigencias de una integración supranacional -el federalismo cooperativo de la RFA- y que el segundo se descentraliza por los requerimientos de un Estado moderno intervencionista que debe acercarse al ciudadano para prestar mejor sus servicios y atender a sus necesidades, siendo la categoría Estado regional el punto máximo de acercamiento al otro polo. Parecía que ese acercamiento, 
con la eventual reclamación de que fuera completo, se olvidaba en España del elemento cooperación y, por supuesto, de la denigrante coordinación, necesaria para que el Estado compuesto pueda funcionar, pero rechazable para algunos en cuanto supone el reconocimiento de una instancia superior y de una unidad a la que deben tender muchas actuaciones para el funcionamiento armónico del sistema.

La crisis sanitaria creada por la covid-19 ha trastocado las posiciones existentes. Fue obvio desde el principio que la lucha contra la pandemia requería de actuaciones coordinadas, perteneciendo la competencia en materia de sanidad a las Comunidades Autónomas, asumida de conformidad con el artículo 148.1. 21 de la Constitución, pero -no nos olvidemos- correspondiendo al Estado las bases y coordinación general ex artículo 149.1.16 CE (coordinación que es parte esencial de la Ley Orgánica 33/2011, de 4 de octubre, General de Salud Pública). Tras titubeos iniciales, pareció que la actuación se inclinaba en favor de una cierta centralización (compra de material sanitario, primer estado de alarma declarado el 14 de marzo de 2020, en el que hasta la sexta prórroga no aparecen las autoridades autonómicas como delegadas), aunque con tendencia al peloteo mutuo Estado-Comunidades Autónomas de la responsabilidad por los errores o resultados negativos cosechados, en particular en el caso de Gobiernos de mayorías diferentes.

Sigue un segundo -y, en cierto modo, ridículo- estado de alarma decretado el 9 de octubre por Real Decreto y limitado en su aplicación a nueve municipios de la Comunidad de Madrid; ridículo por cuanto no se sabe muy bien por qué las medidas autorizadas en otras Comunidades Autónomas no lo fueron para Madrid, tal vez por no citar (¿intencionadamente?) la normativa adecuada (¿iura novit curia?), así como por la apariencia de personalismos/institucionalismos enfrentados que parecía traslucirse en el conflicto de competencias previo al rechazo judicial.

Finalmente, en el tercer estado de alarma, declarado el 25 de octubre por Real Decreto 926/2000, se opta por la autonomía territorial en la adopción de medidas, con efectos positivos y negativos:

- positivos, la posibilidad de flexibilizar aquellas en función de la situación sanitaria en cada Comunidad Autónoma. 
- negativos, por dar lugar a una proliferación de normas de aplicación simultánea o sucesiva, que provocó en el ciudadano indiferencia o desinterés por su conocimiento, y por supuesto, como siempre que el ordenamiento jurídico se complica, condujo a cierta -si no absolutainseguridad jurídica ${ }^{1}$.

A esto se sumó que, en un primer momento, no había certeza plena sobre hasta dónde podían llegar las autoridades de las CCAA en sus decisiones en cuanto a la afectación de los derechos fundamentales: pareciendo excluidos los confinamientos generales domiciliarios -no previstos en el Real Decreto de declaración del estado de alarma-, estaban permitidos confinamientos perimetrales -que limitan, pero no suspenden la libertad de circulación- junto con otras limitaciones a la movilidad (toques de queda, restricciones a la entrada y salida de la Comunidad autónoma), de conformidad con la flexibilidad establecida por aquel en su artículo 10.

\section{SUSPENSIÓN O RESTRICCIÓN DE DERECHOS FUNDAMENTALES}

Esto nos lleva a recordar la discusión inicial, con el paso del tiempo algo superada y que resolverá en su momento el Tribunal Constitucional, de si el estado de alarma era el jurídicamente adecuado para las medidas restrictivas que se impusieron en el primero declarado: ¿implicaban la suspensión de derechos, sólo permitida por el artículo 55 CE para los estados de excepción o de sitio, pero no para el de alarma? ¿Se trataba de restricción o de suspensión de derechos?

Puede resumirse la polémica diciendo que una parte de la doctrina constitucionalista considera que se suspendían derechos fundamentales, lo que no es constitucionalmente posible en un estado de alarma (señaladamente, el profesor Aragón), frente a otra que se inclina por entender que se trata de limitaciones de derechos previstas en los artículos 11 y 12 de la Ley Orgánica 4/1981, de 1 de junio, de los estados de alarma, excepción y

\footnotetext{
${ }^{1}$ T.R. Fernández en "Otros efectos negativos del Covid", $A B C, 9$ enero 2021, considera que uno de esos efectos del que no va a ser fácil librarse es el gravísimo deterioro sufrido por nuestro ordenamiento jurídico, "pieza esencial de eso que convenimos en llamar precisamente Estado de Derecho, en el que han hecho estragos las respuestas que desde el Boletín Oficial del Estado se han ido dando desde el pasado mes de marzo a esta pesadilla".
} 
sitio, siendo además relevantes los supuestos detonantes de estos estados según la Ley Orgánica: crisis sanitarias, como las epidemias, para el estado de alarma (art. 4) y alteraciones del orden público para el de excepción (art. 13).

Puedo aclarar que me encuentro en este segundo grupo. Pero debo reconocer que a la claridad en la interpretación de la norma no ayuda el que se trate de una ley orgánica dictada en los primeros albores constitucionales, hace casi cuarenta años, sin que haya sido necesario aplicarla más que una vez, en diciembre de 2010, con ocasión de la huelga de controladores aéreos -cuyas consecuencias en forma de reclamaciones de responsabilidad patrimonial tal vez todavía coleen-, limitada la declaración al estado de alarma con su duración constitucional inicial de quince días y una única prórroga de un mes.

La misma inseguridad en la aplicación novel plantearon preceptos de otra olvidada ley de los años 80, la Ley Orgánica 3/1986, de 14 de abril, de medidas especiales en materia de salud pública, que atribuye a las autoridades sanitarias competentes la adopción de medidas cuando así lo exijan razones sanitarias de urgencia o necesidad, así como la imposición de sanciones al amparo de otras normas (el art. 15 del Real Decreto 926/2020 se remite al art. 10 de la LO 4/1981, que a su vez se remite genéricamente a las leyes, remisión en cascada ejemplo de deficiente técnica normativa).

Esta inseguridad jurídica se reflejó en un momento inicial en la adopción de resoluciones judiciales posiblemente contradictorias -los supuestos no siempre eran idénticos- de autorización o ratificación de las medidas sanitarias urgentes y necesarias para la salud pública que impliquen privación o restricción de la libertad o de otro derecho fundamental, de conformidad con lo dispuesto en el artículo 8.6 de la Ley 29/1998, de 13 de julio, reguladora de la jurisdicción contencioso-administrativa. De nuevo la necesidad de coordinación, palabra clave a lo largo de estas líneas, llevó a una de las que pueden considerarse medidas de reacción normativa más racionales -se ha reprochado que no haya existido la misma celeridad en la modificación de la normativa sanitaria- para la reforma de la LJCA, mediante la introducción in extremis de una enmienda en el Senado a la que sería Ley 3/2020, de 18 de septiembre, de medidas procesales y organizativas para hacer frente al covid-19 en el ámbito de la Administración de Justicia (resultado de la tramitación como proyecto de ley del Real Decreto-Ley 16/2020, de 28 de abril), para atribuir a los Tribunales Superiores de Justicia la competencia citada "cuando sus destinatarios no 
estén identificados individualmente" (art. 10.8), limitando el conocimiento por los jueces de lo contencioso-administrativo a las medidas plasmadas en actos administrativos singulares que afecten únicamente a uno o varios particulares concretos e identificados de manera individualizada (art. 8.6), en ambos casos siendo parte el Ministerio Fiscal (art. 122 quater), teniendo la tramitación carácter preferente y debiendo resolverse en el plazo de tres días naturales.

La elevación competencial permitía augurar una mayor uniformidad de criterios, fruto de la comunicación entre los TTSSJJ, cuyos Presidentes ya habían celebrado alguna reunión previa, a la vez que la aceleración de los plazos podía contribuir no sólo a la lucha más eficaz contra la epidemia, sino a la seguridad jurídica.

\section{RELACIONES INTERGUBERNAMENTALES Y COMPETENCIAS PARLAMENTARIAS}

No voy a entrar en las dudas sobre las competencias y rango jurídico de los acuerdos del Consejo Interterritorial del Sistema Nacional de Salud, "órgano permanente de coordinación, cooperación, comunicación e información de los servicios de salud entre ellos y con la Administración General del Estado", según la definición dada por el artículo 69 de la Ley 16/2003, de 28 de marzo, de cohesión y calidad del Sistema Nacional de Salud, al que el artículo 13 del Real Decreto 926/2020 atribuye, para garantizar la necesaria coordinación en la aplicación de las medidas contenidas en el mismo, "adoptar a estos efectos cuantos acuerdos procedan, incluidos, en su caso, el establecimiento de indicadores de referencia y criterios de valoración del riesgo".

Prefiero comentar brevemente el descubrimiento de otro mecanismo de cooperación entre Estado y CCAA como es la Conferencia de Presidentes, calificado en la página web del Ministerio de Presidencia, Relaciones con las Cortes y Memoria democrática como la cúspide del conjunto de órganos de cooperación multilateral, cuya creación "ha sido la iniciativa más importante de los últimos años, tanto política como institucional, para el desarrollo de la cooperación, ya que culmina el sistema de Conferencias Sectoriales"2.

\footnotetext{
${ }^{2}$ Consulta 4 enero 2021.
} 
Constituida el 28 de octubre de 2004, la Conferencia celebró seis reuniones hasta 2017, estableciendo su reglamento interno adoptado en 2009 su sede en el Senado -aunque puede celebrar reuniones en las CCAA y en las Ciudades Autónomas de Ceuta y Melilla-, así como su reunión anual.

Como digo, este mecanismo de cooperación fue redescubierto -a la vez que el Senado olvidado- durante la pandemia, convocando el Presidente del Gobierno 14 reuniones extraordinarias durante el primer estado de alarma, celebradas por videoconferencia desde La Moncloa, y una posterior el 31 de julio en San Millán de la Cogolla, ya con asistencia de la Presidenta del Senado, en cuya nota de prensa se anunciaba un acuerdo sobre la fijación de una periodicidad aproximada de una vez al mes durante la permanencia del covid-19. A ella seguirían, efectivamente, otras dos reuniones el 4 de septiembre (en cuya nota de prensa se ensalza la cogobernanza desarrollada y se afirma la necesidad de continuar articulando una respuesta coordinada de todos los gobiernos frente al virus) y el 26 de octubre, vigente ya el tercer estado de alarma consecuencia del covid-19, pero no a lo largo de este, cuando la descentralización de medidas podía exigir mayor coordinación entre ellas.

Hemos dicho que durante la crisis se olvidó que el Senado era la sede de la Conferencia de Presidentes. En realidad, el Senado como Cámara de representación e integración territorial ha sido olvidado tout court durante la pandemia ${ }^{3}$. Apenas una única reunión de la Comisión General de Comunidades Autónomas celebrada el 30 de abril de 2020, descafeinada por el rango de los asistentes.

Sólo a posteriori empiezan a levantarse algunas voces sobre ese olvido/apartamiento voluntario durante los momentos álgidos de la crisis y su no utilización como organismo o mecanismo de relación Estado-Comunidades Autónomas: de representación territorial, como lo califica el artículo 69.1 de la Constitución. Así, el anterior Presidente de la Alta Cámara Manuel Cruz recordaba el acomodo natural de la citada Conferencia en el Senado 4 .

\footnotetext{
${ }^{3}$ Véase P. García-Escudero Márquez, "Actividad y funcionamiento de las Cortes Generales durante el estado de alarma por COVID-19", Cuadernos Manuel Giménez Abad, Monografía 8, 2020, págs. 23-24.

${ }^{4}$ M. Cruz, "El Senado: donde pararse a pensar", El País, 2 enero 2021: "La loable iniciativa de activar la conferencia de presidentes de Comunidades Autónomas -el organismo informal más federal del que disponemos- tal y como se hizo durante la pandemia, debería encontrar su acomodo natural en las actividades del Senado. Que dichas conferencias, así como las diversas conferencias sectoriales que en el futuro se celebren, tengan lugar en su sede es algo
} 
En otro lugar he estudiado la actividad de los parlamentos españoles sobre la pandemia, incluyendo la actuación del Congreso de los Diputados en el control de los estados de alarma (recepción de la comunicación y autorización de las prórrogas) y la convalidación de los numerosos decretos-leyes, la difuminada del Senado y la de los Parlamentos autonómicos ${ }^{5}$.

Allí se describe cómo en general se retoma el control ordinario de los ejecutivos lo antes posible, aproximadamente un mes después de la declaración del primer estado de alarma, y la utilización de instrumentos de seguimiento y control como las comisiones de estudio e investigación.

Sólo dos comentarios quiero añadir aquí:

\section{A) Prórroga del estado de alarma por seis meses}

Resulta insólita la prórroga por seis meses del tercer estado de alarma en la misma sesión plenaria en la que se presentaba la comunicación de su declaración, en puntos del orden del día debatidos acumuladamente el 29 de octubre de 2020.

La solicitud de prórroga por el Gobierno plantea distintas cuestiones (algunas afectan quizá a la propia política sanitaria):

- desde cómo se sabe que se necesita tal plazo desde el comienzo del periodo inicial de declaración;

- pasando porque, aunque la duración de las prórrogas no está fijada por la Constitución, parece debe ser proporcionada a los plazos máximos que sí establece para la declaración de alarma (quince días, 116.2 CE) y

\footnotetext{
que algunos llevábamos tiempo reclamando y que debería institucionalizarse". En este artículo, en relación con la aprobación sin enmiendas en la Segunda Cámara de la LOMLOE o Ley Celaá, el ex-Presidente reclama asimismo el protagonismo del Senado en el debate sobre el independentismo catalán. Véase también en M. A. Agudo Zamora, Reforma constitucional y Estado autonómico, Tecnos, Madrid, 2020, págs.70 y siguientes, las propuestas contenidas en el Documento Propuestas para un debate sobre la reforma territorial desde las Universidades andaluzas, coordinado por X. Coller, con el objetivo, entre otros, de subsanar la escasa coordinación entre el Estado y las CCAA y de estas entre sí.

${ }^{5}$ P. García-Escudero Márquez, "Actividad y funcionamiento de los Parlamentos españoles en la crisis sanitaria por COVID-19", en D. Barceló, S. Diaz Ricci, J. García Roca, M. E. Guimaráes, COVID-19 y parlamentarismo. Los parlamentos en cuarentena, UNAM-IDP UCM, México, 2020; y un estudio más completo, "La ductilidad del Derecho parlamentario en tiempos de crisis. Actividad y funcionamiento de los Parlamentos durante el estado de alarma por COVID19", Teoría y Realidad Constitucional no 46, 2020, págs. 271-308.
} 
de excepción (treinta días prorrogables por un periodo igual, 116.3 CE) y porque tan amplio espacio temporal impide una adaptación gradual a las circunstancias, aunque ello podría tener cabida en el régimen flexible establecido por el Real Decreto hasta cierto punto, pero no en la medida necesaria para luchar contra la terrible tercera ola de la enfermedad en enero de 2021, lo que generó disensiones ${ }^{6}$ entre el Gobierno y las Comunidades Autónomas, las cuales solicitaban poder endurecer las medidas cubiertas por el Real Decreto 926/2020.

- hasta llegar a la cuestión de mayor relevancia, que es el relegado papel del Congreso en esta nueva situación.

En efecto, se pasa de la autorización de prórrogas quincenales en el primer estado de alarma, con la consiguiente posibilidad de introducir condicionamientos y modificaciones en cada una de ellas, a una comparecencia informativa del Presidente del Gobierno cada dos meses (iy una mensual del Ministro de Sanidad! ${ }^{7}$ ), lo que obviamente supone una disminución en la intensidad del control del propio estado de alarma, más allá del ordinario sobre los decretos-leyes que se dicten a través de su convalidación o derogación, así como mediante los instrumentos de control semanal (preguntas, interpelaciones) u otros (comparecencias de Ministros, etc...).

De este modo, se eluden los debates periódicos -antes quincenales- de la prórroga, donde podrían alzarse en sede parlamentaria las voces de la oposición al más alto nivel, así como las votaciones que permiten comprobar la subsistencia, incremento o disminución del apoyo inicial ${ }^{8}$.

\footnotetext{
${ }^{6}$ El Presidente de la CA Castilla y León acordó unilateralmente la ampliación del toque de queda, desde las 20 horas, en base a una interpretación del término "modular" las medidas, actuación permitida tras las modificación del RD de declaración por la prórroga autorizada. El Gobierno, que no compartía la interpretación, recurrió el acuerdo ante el Tribunal Supremo. Sobre la deficiente técnica normativa que podía dar lugar a tales diferencias, M. Izquierdo Carrasco, "20.00 horas, un cierre con base legal ya", El Mundo, 19 enero 2021. Un mes después del acuerdo el TS suspendió cautelarmente la medida adoptada.

${ }^{7}$ La autorización de la prórroga modifica la comparecencia quincenal prevista por el art. 14 en el texto original del RD 926/2000 en caso de prórroga.

${ }^{8}$ Esta elusión se expresa claramente en la justificación atribuida a García Page, Presidente de Castilla-La Mancha (El Mundo on line, Última hora Covid-19, 21 enero 2020), de la posición del Ministro de Sanidad en el sentido de no modificar las medidas del estado de alarma para la tercera ola, en la conflictiva situación antes expuesta: "el Congreso se ha convertido en un suplicio para el Gobierno".
} 


\section{B) Papel de los Parlamentos autonómicos}

El segundo aspecto a destacar de cara al futuro es el papel que han asumido o deben asumir los Parlamentos autonómicos desde el momento en que las medidas contra la pandemia se trasladan a su ámbito de control (¿o por ser delegadas no pueden ser controladas por ellos?).

No es generalizable a todos, pero cabría aventurar que a lo largo de los años se ha criticado el escaso grado de control desarrollado por los parlamentos territoriales, en particular aquellos con mayorías absolutas durante largos periodos. De su letargo les sacó primero la fragmentación resultado de últimas elecciones; pero, apenas despertados, la pandemia ha hecho revivir, solventadas las dificultades de funcionamiento, instrumentos como las comparecencias frecuentes de presidentes y consejeros o las comisiones de investigación, así como -allí donde existe la competencia gubernamental- la convalidación de numerosos decretos-leyes.

Si el control comenzó durante el primer estado de alarma pandémico, en el tercero (segundo general a toda España) ha debido incrementarse, a la par que el ámbito de decisión atribuido al Ejecutivo autonómico. Merece un estudio la intensidad y calidad de este control, más allá de las apariencias estadísticas o formales.

\section{HACIA EL FUTURO}

El futuro todavía no existe. Seguimos anclados en el presente de la lucha contra la pandemia y sus sucesivas oleadas o rebrotes (los cuales, por cierto, plantearon también problemas jurídicos cuando surgieron por primera vez fuera del paraguas del estado de alarma inicial).

En este presente que nos lleva al futuro se destacan como efectos positivos de la crisis la digitalización o el teletrabajo. Desde el punto de vista que ha enfocado esta aportación, el de la cooperación entre Estado y CCAA y estas entre sí (recuérdese como ejemplo la reunión de los Presidentes de las Comunidades limítrofes de Castilla y León, Madrid y Castilla-La Mancha) y la imprescindible coordinación estatal, cabría reforzar los instrumentos redescubiertos y no dejarlos caer en el olvido -como las propias relaciones 
intergubernamentales- una vez que la necesidad deje de apremiar. Tal vez sea mucho esperar que se haya aprendido la lección de que autonomía y cooperación constituyen un binomio indisoluble.

Sería también deseable que las filiaciones políticas no dificultaran las relaciones entre el Gobierno y las Comunidades Autónomas o que en asuntos tan relevantes no prime el oportunismo político, pero esto ya es pura utopía, sobre todo a medida que puedan aproximarse confrontaciones electorales. No es este un mensaje esperanzador, pero -pese a todo- confiemos en que la propia naturaleza retorne a su ser, cualesquiera que sean los aciertos o los errores políticos en la lucha contra la pandemia. 